\title{
ANALISIS PERBANDINGAN PREDISKSI OBAT DENGAN MENGGUNAKAN METODE ABC ANALISYS DAN SVR PADA APLIKASI "MORBIS"
}

\author{
Tutik Maryana *1 ${ }^{1}$, Kusrini ${ }^{2}$, Hanif Al Fatta ${ }^{3}$ \\ 1,2,3 Magister Teknik Informatika, Fakultas Ilmu Komputer, Universitas Amikom Yogyakarta \\ E-mail: *1 tutik.maryana@ students.amikom.ac.id, ${ }^{2}$ kusrini@ students.amikom.ac.id, ${ }^{3}$ hanif.a@ amikom.ac.id
}

\begin{abstract}
Abstrak - Permasalahan rumah sakit mengenai pengolahan persediaan obat adalah kondisi obat yang habis, dikarenakan rumah sakit dalam satu tahun mengeluarkan $33 \%$ dari biaya investasi untuk investasi obat. Untuk mengtasi permasalahan diatas rumah sakit harus memiliki pengeloaan logistic dengan baik, cara pengelolaan adalah dengan melakukan perencanaan yang baik. Penulis akan memakai algoritma ABC Analysis dan SVR. ABC Analysis akan digunakan untuk proses klasifikasi obat yaitu dengan cara membagi obat manjadi tiga kelompok utama berdasarkan kepentingan yaitu kelompok A, B dan C. Penulis akan menggunakan metodo SVR untuk menghitung prediksi obat. Hasil penelitian ini adalah ABC analisys dapat membagi obat. Menjadi tiga bagian yaitu kelompo A 276 item dengan presentase $22,96 \%$ dari jumlah item keseluruhan, kelompok B sejumlah 396 item dengan presentase $33,11 \%$ dan $C$ sejumlah 528 dengan presenrase 43,94\% dengan kesluruhan obat adlah 1202 item obat. Pengujian prediksi dilakukan dengan cara mengambil sample lima obat dari hasil klasifikasi. Proses perhitungan SVR adalah membandingkan metode preprocessing linier scaling dan z normalization. Hasil dari penelitian tersebut adalah MAPE menunjukan bahwa dengan menambahkan preprocessing dengan linier scaling dapat membuat proses SVR lebih optimal dari pada menggunakan z normalization dan perhitungan dengan klasifikasi ABC analisys.
\end{abstract}

Kata Kunci - SVR, Klasifikasi, Prediksi , ABC Analisys.

Abstract - The hospital's problem regarding processing drug supplies is drug condition is depleted, because it has spent $33 \%$ of the investment on drug in year. To deal with the above problems the hospital must have good logistics management, the way to manage it is by doing good planning. The writer use ABC Analysis and SVR. ABC Analysis will be used for the drug classification, namely by dividing drugs into three main groups based on interests, namely groups A, B and C. The author use the SVR to calculate drug predictions. The results of this study are ABC can share drugs. Into three parts group A 276 items with a percentage of $22.96 \%$ of the total number of items, group B 396 items with a percentage of $33.11 \%$ and $C 528$ with a percentage of $43.94 \%$ with the overall drug being 1202 items. Prediction is done by taking samples of five drugs from the classification results. The SVR process is comparing the linear scaling preprocessing method and $\mathrm{z}$ normalization. The results are MAPE shows that by adding preprocessing with linear scaling can make the SVR process more optimal than using z normalization and calculations with ABC.

Keywords - SVR, Classification, Prediction, ABC Analyst.

\section{PENDAHULUAN}

Obat adalah bagian penting dalam proses pelayanan kesehatan, seperti rumah sakit, klinik ataupun pelayanan kesehatan lainnya. Pengelolaan obat adalah termasuk dalam indikator mutu pelayanan dalam bidang kefarmasian. Tahapan proses pengelolaan obat adalah sebagai berikut mulai dari seleksi, kontribusi, pengadaan terakhir adalah penggunaan obat.standar pengelolaan obat yang baik dan sesuai adalah dengan. Menggunakan sistem atau metode yang dapat menjamin stok obat tersedia pada setiap unit pelayanan di rumah sakit atau klinik. Proses Pengolahan obat dapat dipengaruhi oleh beberapa komponen seperti personil atau sumber daya manusia, fasilitas kesehatan, perlengkapan kesehatan, harga, administrasi dan sistem informasi. Pengelolaan obat yang baik bukan hanya berdampak pada peningkatan akses obat tetapi juga akan berdampak pada penilaian masyarakat terhaap tingakat kepuasan pelanggan terhadap pelayanan dalam sebuah instansi [1].
Dalam rentan waktu tertentu rumah sakit mengeluarkan $33 \%$ biaya dari keseluruhan biaya investasi hanya untuk biaya obat. 33\% adalah biaya yang besar, oleh karena itu personil atau sumber daya manusia membutuhkan pengelolaan persediaan obat yang sesuai dan maksimal, karena permasalahan itu akan berdampak pada pendapatan rumah sakit atau klinik [2]. Unit Farmasi harus mengelola ribuan jenis obat dalam jumlah bervariasi untuk keberlangsungan transaksi setiap hari pada rumah sakit atau klinik [3]. Masalah yang tejadi pada pengelolaan persediaan obat adalah pada saat obat tersebut dibutuhkan atau ada konsumen yang akan membeli, obat tersebut habis atau dalam keadaan out stok. Permasalahan tersebut sering terjadi karena pada unit farmasi melakukan kesalahan dalan pengelolaan dan perencanaan persediaan obat[4]. Review yang dilakukan dari penelitian yang telah dilakukan oleh Silviana Agstami pada tahun 2014 mendapatkan hasil bahwa klasifikasi dengan menggunkan ABC Analisys memberikan informasi yang lebih akurat serta mampu menunjukka usulan 
biaya yang dikonsumsi pada proses produksi diabandingkan dengan motedo tradisional pada kasus klasifikasi obat. Selain itu penelitian yang dilakukan oleh Rathanaksambath Ly dan Marrokot Raweewan pada penelitian yang berjudul Flexible ABC Inventory Clasification mendapatkan hasil bahwa dengan melakukan klasifikasi berdasarkan penjualan pada periode tertentu, maka dapat menghasikan klasifikasi yang memaksimalkan laba dengan kondisi memiliki anggara persediaan terbatas dab ruang gudang terbatas[5].

Acuan penelitian selanjutnya adalah penelitian tentang mendiagnosa pasien kanker payudara dengan mrode support vector regression (SVR). Pada penelitian tersebut peneliti menggunakan variable predictor, respon, intermediate findings, usia serta letak abnormal. Hasil dari penelitian tersebut adalah besar nilai akurasi adalah $94.34 \%$, hasil tersebut lebih maksimal dari pada dengan metode regresi logistik biner dengan akurasi $88.72 \%$. dari penelitian tersebut dapat diambil kesimpulan bahwa SVR memiliki performa lebih baik dari pada metode SVM[6].

Pada kasus yang terjadi pada rumah sakit yang dijadikan objek oleh penelitia adalah proses prediksi penjualan obat untuk menentukan stok aman dibulan berikutnya yang dilakukan oleh petugas pengadaaan barang adalah dengan cara mengambil data penjualan bulan ini kemudian dirata-rata penjualan setiap hari maka akan didapatkan data rata-rata penjualan per hati. Data tersebut menjadi dasar untuk melakukan perkiraan penjualan di bulan berikutnya yang kemudian akan dijadikan dasar untuk melakukan pengadaan obat. Berdasarkan cara yang dilakukan oleh petugas pengadaan tersebut terhitung data dari januari November 2019 kamu memperoleh data bahwa dari 11 bulan tersebut terdapat 6 bulan rumah sakit mengalami out stok atau obat habis. Sehingga dapat memperlambat pelayanan[7].

Dalam rangka untuk mengurangi resiko yang terjadi di rumah sakit tersebut, cara yang dapat dilakukan adalah dengan cara melakukan metode prediksi [8]. Proses prediksi dapat yang akan dilakukan adalah dengan cara mencari metode yang paling optimal atau metode yang dapat menghasilkan tingkat eror paling kecil, metode yang akan kami lakukan adalah dengan membandingkan metode SVR dengan menambahkan preprocessing linier scaling dan normalisasi dengan menambahkan proses klasifikasi.

Penulis memilik metode ABC Analisys karena metode tersebut mampu mengendaliakan persediaan barang dengan memperhatikan kelompok barang sesuai dengan tingkat kepentingan masing-masing kelompok barang, pada metode ini barang diklasifikasikan kedalam kelas $\mathrm{A}, \mathrm{B}$ dan $\mathrm{C}$ berdasarkan nilai penjualan. Sehingga perusahaan bisa melihat tingkat kepentingan barang tersebut.

\section{METODE PENELITIAN}

\section{A. Pengumpulan Data}

Metode pengumpulan data yang kami lakukan adalah dengan cara mengumpulkan data primer[9], yaitu kami mengambil data langsung dari sumber data pertama yaitu dari aplikasi yang digunakan untuk melakukan kegiatan operasional di rumah sakit. Data yang penulis dapatkan adalah data yang di export langsung dari database yaitu berupa data .dmp. Alur proses pengumpln data dijelaskan pada Gambar 1 Proses pengambilan data berikut:

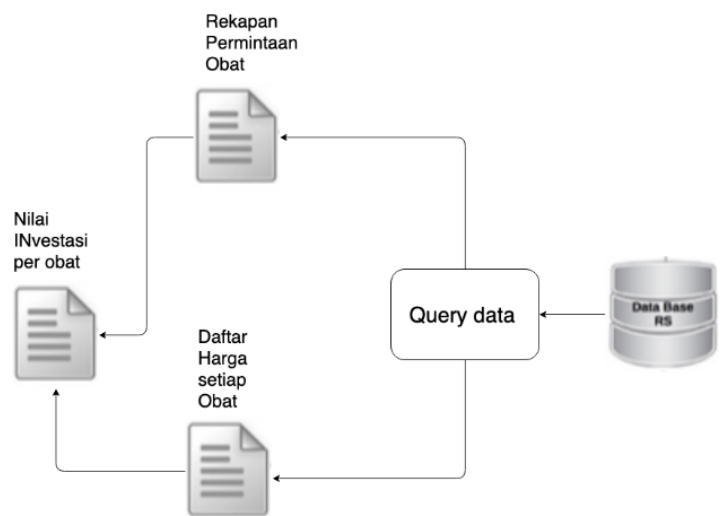

Gambar 1. Alur Proses Pengambilan Data

\section{B. Analisa Data}

Metoda Analisa yag digunakan dalam penelitian ini yaitu analisasi kuantitatif. Dalam proses klasifikasi obat yang dijalankan berisi keluaran berpa klasifikasi obat dengan menghasilkan pembagian obat menadi kelompok A, B dan C. Proses selanjutnya adalah melakuakan proses optimasi prediksi obat dengan metode SVR dengan menambahkan proses pada praproseccing data[10]. Berikut adalah alur Analisa yang dilakukan :

a. Analisa pada proses klasifikasi dapat digambarkan pada alur berikut

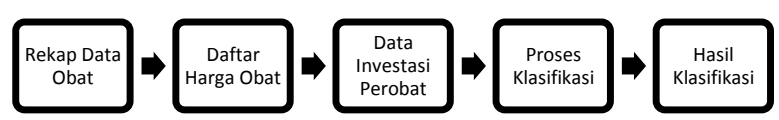

Gambar 2. Klasifikasi dengan ABC Analisys

Dari Gambar 2 Klasifikasi dengan ABC analisys dapat diambil penjelasan bahwa proses klasifikasi obat didasarkan pada rekap data obat dan harga obat. Kedua variable tersebut berfungsi untuk mengetahui jumlah investasi pada setiap obat[11]. Data yang penulis dapatkan kemudian diurutkan mulai dari 
nilai tertinggi ke nilai tertendah sesuai dengan nilai investasi dan presentasi komulatif. Selanjutnya adalah tahapan klasifikasi yang pada akhirnya akan menampilkan hasil mengelompokkan obat kelompok A, B dan C[12].

b. Metode Pengolahan Data untuk Prediksi

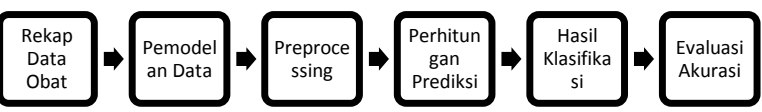

Gambar 3. Metode Pengolahan Data untuk Prediksi

Dari Gambar 3 Metode Pengolahan Data untuk Prediski, dapat dijelaskan bawha proses pengolahan data terbagi menjadi 6 tahapan yaitu rekapan data obat, pemodelan data, preprocessing, perhitungan prediksi, hasil klasifikasi dan evaluasi akurasi[9]

\section{Alur Penelitian}

Berikut adalah detail alur penelitian yang akan dilakukan oleh penulis, untuk penjabaran alur penelitian adalah sebagai berikut :

1. Identifikasi masalah, yaitu proses menjabaran permasalahan objek penelitian dan membuat rumusan masalash berdasarkan penjabaran masalah yang telah dilakukan.

2. Tinjauan Literatur, yaitu sebuah proses untuk mencari rujukan atau sumber ilmu, contoh penelitian yang serupa dan contoh dataset yang bisa dimanfaatkan

3. Penentuan Algoritma atau metode, yaitu proses pencarian metode atau algoritma yang relevan dan terkait langsung dengan penelitian yang sedang dilakukan. Pada proses ini terjadi juga penentuan pilihan-pilihan variasi dan parameter yang akan penulis terapkan pada penlitian yang dilakukan.

4. Pengumpulan data, yaitu proses yang dilakukan setelah proses penentuan lagoritma selesai. Dasar dari pengumpulan data adalah algoritma yang telah ditentukan beserta variasi dan parameter yang dipilih. Pengumpulan data yang berhasil adalah mendapatkan data dari jenis dataset, jumlah dan varasi yang diperlukan sesuai dengan kebutuhan.

5. Pengolahan data, yaitu proses yang dilakukan setelah data sudah diperoleh. Data yang sudah diperoleh akan menjadi dasar untuk pengolahan data. Berikut adalah tahapan pengolahan data yaitu query database, proses preprocessing data menggunakan scalling linier dan normalisai data.

6. Proses Peramalan, yaitu proses yang dilakukan untuk mengetahui kondisi yang akan datang. Dalam proses ini penulis menggunakan metode SVR yang berfungsi untuk melakukan permalam obat kemudian mencari nilai yang paling optimal dengan membandingkan preprocessing scalling, normalisasi, dan klasifikasi.

7. Pengambilan kesimpulan, yaitu proses yang dilakukan pada tahap akhir penelitian. Pada proses ini penulis menampilkan data hasil penelitian dan mencari cara untuk evaluasi sehingga mendapatkan hasil yang optimal.

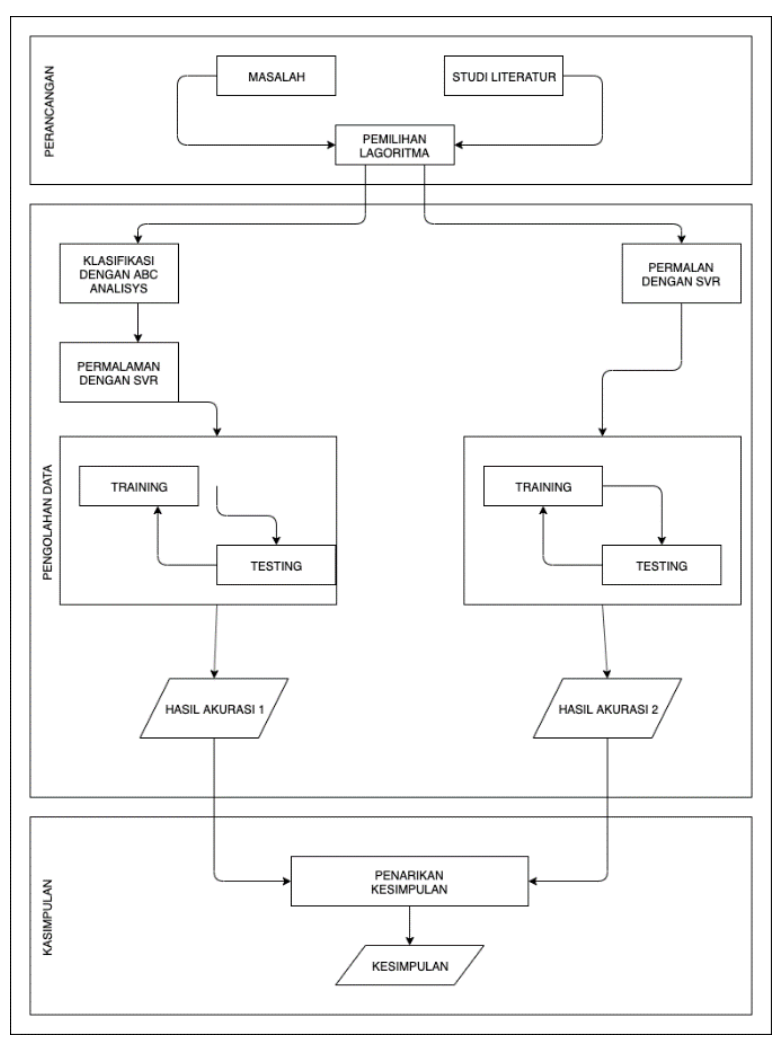

Gambar 5. Aliran Proses Penelitian

\section{HASIL DAN PEMBAHASAN}

\section{A. Klasifikasi ABC Anlisisys}

Hasil dari proses klasifikasi yang dilakukan penulis dengan menggunakan metode $\mathrm{ABC}$ analisys adalah dengan cara mengelompokkan menjadi tiga kelompok yaitu kelompok A, B dan C[12]. Hasil yang penulis dapatkan adalah sesuai dengan data pada Tabel 1.

Tabel 1. Hasil Klasifikasi ABC Analisys

\begin{tabular}{|l|r|r|r|r|}
\hline $\begin{array}{c}\text { Jenis } \\
\text { Kel. }\end{array}$ & $\begin{array}{c}\text { QT } \\
\text { Y }\end{array}$ & $\begin{array}{c}\text { Presentase } \\
\text { Jumlah } \\
\text { Item }\end{array}$ & $\begin{array}{c}\text { Total Investasi } \\
\text { (dalam Rp) }\end{array}$ & $\begin{array}{c}\text { Presenta } \\
\text { se Total } \\
\text { Investasi }\end{array}$ \\
\hline A & 276 & $22,96 \%$ & 5.913 .997 .261 & $75,61 \%$ \\
\hline B & 389 & $33,11 \%$ & 1.005 .950 .285 & $12,86 \%$ \\
\hline C & 528 & $43,93 \%$ & 901.849 .247 & $11,53 \%$ \\
\hline Jumlah & $\mathbf{1 2 0 2}$ & $\mathbf{1 0 0 \%}$ & $\mathbf{7 . 8 2 1 . 7 7 6 . 7 9 3}$ & $\mathbf{1 0 0 \%}$ \\
\hline
\end{tabular}




\section{Proses Peramalan Menggunakan Data Hasil Klasifikasi}

Proses permalan dilakukan menggunakan data sample 5 obat dengan inveestasi tertinggi yaitu obat yang masuk dalam klasifikasi A, uji predisksi dilakukan dengan metode fold cros falidation. Berikut adalah parameter yang digunakan oleh penulis $\mathrm{C}=1, \mathrm{C}=10$ dan $\mathrm{C}=100$ dan $\varepsilon=0.1$. Hasil uji untuk 5 item obat dapat dilihat pada Tabel 2 .

Tabel 2. Hasil Pengujian

\begin{tabular}{|l|l|l|l|}
\hline \multirow{2}{*}{ Nama Obat } & \multicolumn{3}{|c|}{ MAPE (dalam \%) } \\
\cline { 2 - 4 } & $\mathbf{C = 1}$ & $\mathbf{C = 1 0}$ & $\mathbf{C = 1 0 0}$ \\
\hline Cefixime Hexpharm & 47,67 & 40,75 & 39,23 \\
\hline Lansoprazol Nulab & 39,87 & 29,96 & 30,29 \\
\hline $\begin{array}{l}\text { Methyl Prednisolon } \\
\text { Hexpharm }\end{array}$ & 56,87 & 49,76 & 65,78 \\
\hline Paracetamol Bernofarm & 38,21 & 39,29 & 30,95 \\
\hline Curcuma Kaleng & 35,98 & 33,83 & 31,90 \\
\hline
\end{tabular}

Berdasarkan pengujian yang telah penulis lakukan, MAPE yang dihasilkan pada masing-masing obat adalah rata-rata ditas $30 \%$.

\section{Proses Permalan Menggunakan Preprocessing} Linier Scalling

Prose permalan menggunakan preprocessing linier menggunkaan satu contoh data obat yaitu CEFAT CAP 500MG, obat tersebut menunjukan bahwa pola data permintaan dapat dilihat pada Tabel 3.

Tabel 3. Deskripsi Statistic CEFAT CAP 500MG

\begin{tabular}{|l|l|l|}
\hline Min & Max & Nilai \\
\hline 208 & 490.2 & 759 \\
\hline
\end{tabular}

Uji coba yang dilakukan oleh penulis adalah dengan menggunakan K-Fold Cross falidation dengan nilai $\mathrm{K}=5$ sehingga membagi menjadi 5 blok yang sama mempunyai Panjang data yang sama.

Tabel 4. Hasil Pengujian (Data Normalisasi)

\begin{tabular}{|c|c|c|c|}
\hline \multirow[b]{2}{*}{ UJI KE } & \multicolumn{3}{|c|}{ MAPE (\%) } \\
\hline & $\begin{aligned} \mathrm{C}= & 1 \text { dan } \varepsilon \\
& =0.1\end{aligned}$ & $\begin{array}{c}\mathrm{C}=10 \text { dan } \\
\varepsilon=0.1\end{array}$ & $\begin{array}{c}\mathrm{C}=100 \\
\text { dan } \varepsilon= \\
0.1\end{array}$ \\
\hline 1 & 15,86 & 15,77 & 16,33 \\
\hline 2 & 16,89 & 14,7 & 14,08 \\
\hline 3 & 20,0 & 16,75 & 16,61 \\
\hline 4 & 28,68 & 22,62 & 22,88 \\
\hline 5 & 17,72 & 17,73 & 18,03 \\
\hline Rata-rata & 19,83 & 17,51 & 17,59 \\
\hline
\end{tabular}

Sesuai dengan hasil pengujian pada Tabel 4 , MAPE terendah adalah 18,09 dengan $\mathrm{C}=10$ dan $\varepsilon=0,1$ . Hasil tersebut adalah lebih optimal dari pada permalan SVR tanpa preprocessing data.

\section{Proses Pengujian Data Normalisasi}

Proses peramalan menggunakan preprocessing linier menggunkaan satu contoh data obat yaitu CEFAT CAP 500MG, obat tersebut menunjukan bahwa pola data permintaan dapat dilihat pada Tabel 5 berikut :

Tabel 5. Deskripsi Statistic CEFAT CAP 500MG

\begin{tabular}{|l|l|l|l|l|l|}
\hline Min & Max & Median & Mean & $3^{\text {rd }} \mathrm{Qu}$ & Max \\
\hline 208 & 490.2 & 759 & 584.7 & 684 & 951 \\
\hline
\end{tabular}

Uji coba yang dilakukan oleh penulis adalah dengan menggunakan K-Fold Cross falidation dengan nilai $\mathrm{K}=5$ sehingga membagi menjadi 6 blok yang sama mempunyai Panjang data yang sama.

Tabel 6. Hasil Pengujian (Data Scaling Linier)

\begin{tabular}{|c|c|c|c|}
\hline \multirow{2}{*}{ UJI KE } & $\begin{array}{c}\mathrm{3}=1 \text { dan } \varepsilon \\
=0.1\end{array}$ & $\begin{array}{c}\mathrm{C}=10 \text { dan } \\
\varepsilon=0.1\end{array}$ & $\begin{array}{c}\mathrm{C}=100 \\
\text { dan } \varepsilon= \\
0.1\end{array}$ \\
\hline 1 & 15,86 & 15,69 & 15,65 \\
\hline 2 & 15,56 & 15,75 & 15,66 \\
\hline 3 & 19,22 & 18,68 & 18,63 \\
\hline 4 & 26,64 & 25,89 & 26,75 \\
\hline 5 & 17,42 & 17,43 & 17,44 \\
\hline Rata-rata & 18,09 & 18,69 & 18,83 \\
\hline
\end{tabular}

Sesuai dengan hasil pengujian pada Tabel 6 , MAPE terendah adalah 18,09 dengan $\mathrm{C}=10$ dan $\varepsilon=$ $17,51 \%$. Hasil tersebut adalah lebih optimal dari pada permalan SVR dengan klasifikasi $\mathrm{ABC}$ dan data normalisasi.

\section{Grafik Perbandingan}

Berdasarkan penelitian dengan studi kasus yang penulis uraikan, maka dihasilkan grafik perbandingan perhitungan ditunjukkan pada Grafik 6. berikut :

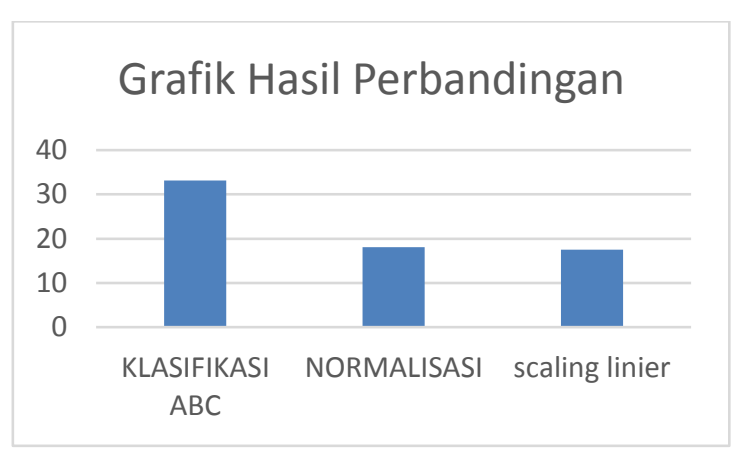

Gambar 6. Grafik Hasil Perbandingan

\section{KESIMPULAN}

Hasil penelitian untuk kasus optimasi peramalan penjualan obat dengan menggunakan SVR adalah dengan menggunkan proses preprocessing data dengan scaling linier mendapatkan hasil lebih optimal 
yaitu dengan MAPE $17,51 \%$, angkat tersebut lebih sedikit dari pada dengan menggunkan preprocessing data dengan normalisasi yaitu mendapatkan nilai MAPE 18,09 \% dan menggunkan klasifikasi ABC analisys dengan nilai MAPE $33,15 \%$.

\section{SARAN}

Pada penelitian selanjutnya perlu modifikasi pada kernel yang dipakai, pada penelitian ini peneliti menggunakan kernek RBF dan mendapatkan hasil bahwa untuk mengoptimalkan atau memaksimalkan permalan dengan menggunakan SVR adalah dengan menambahkan preprosesing data yaitu dengan menggunakan scaling linier. Untuk klasifikasi yang penulis gunakan adalah metode $\mathrm{ABC}$ analisis untuk penelitian selanjutnya bisa menggunkaan klasifikasi yang berbeda untuk melakukan percobaan optimasi permalan dengan menggunakan metode SVR.

\section{DAFTAR PUSTAKA}

[1] Santoso, B. 2007. Data Mining Teknik Pemanfaatan Data untuk Keperluan Bisnis. Yogyakarta: Graha Ilmu.

[2] Kelle, P., Woosley, J., \& Schneider, H. (2012). Pharmaceutical supply chain specifics and inventory solutions for a hospital case. Operations Research for Health Care, 1(2-3), 54-63. doi:10.1016/j.orhc.2012.07.001

[3] Santoso, B. 2007. Data Mining Teknik Pemanfaatan Data untuk Keperluan Bisnis. Yogyakarta: Graha Ilmu.

[4] Smola, A.J. dan Scholkopf, B. 2003. A Tutorial on Support Vector Regression. Technical Report, Neurocolt.

[5] Uthayakumar, R., \& Priyan, S. (2013). Pharmaceutical supply chain and inventory management strategies for optimization: A study on pharmaceutical company and hospital. Operations Research for Health Care. doi:10.1016/j.orhc.2013.08.001

[6] Kumar, S., \& Chakravarty, A. (2015). ABC-VED analysis of expendable medical stores at a tertiary care hospital. Medical Journal Armed Forces India, 71(1), 24-27. doi:10.1016/j.mjafi.2014.07.002Lamport, L., 1994, LaTeX: A Document Preparation System, Second Edition, Addison Wiley, Canada

[7] Er, M., Laili, E. N., \& Renny, P. K. (2011). Classification of Hospital Pharmaceutical Drug Inventory Items by Combining $\mathrm{ABC}$ Analysis and Fuzzy Classification. International Conference on Advanced Computer Science and Information System (ICACSIS 2011), 978-979.

[8] Shiau, J.-Y., Li, X., \& Zheng, M.-J. (2012). Drug Inventory Control For Outpatien Services. Logistics Management, (July), 16-18.

[9] Fruggiero, F., Iannone, R., Martino, G., Miranda, S., \& Riemma, S. (2012). A forecast model for pharmaceutical requirements based on an artificial neural network. Service Operations and Logistics, and Informatics (SOLI), 2012 IEEE International Conference on, 263-268.

[10] Makridakis, S. (1986). The art and science of forecasting An assessment and future directions. International Journal of Forecasting, 2(1), 15-39. doi:10.1016/0169-2070(86)90028-2

[11] Scholz- Reiter, B., Heger, J., Meinecke, C., \& Bergmann, J. (2012). Integration of demand forecasts in $\mathrm{ABC}-\mathrm{XYZ}$ analysis: practical investigation at an industrial company.

[12] Vapnik, V. N. (1999). An overview of statistical learning theory. IEEE Transactions on Neural Networks / a Publication of the IEEE Neural Networks Council, 10(5), 988-999. doi:10.1109/72.78864 